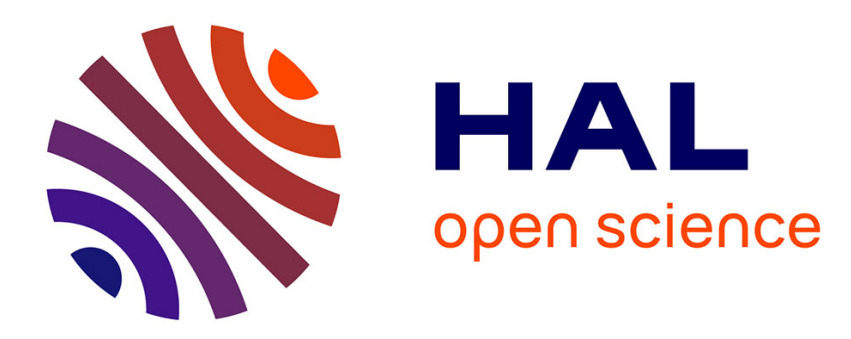

\title{
A New Experimental Method of the Determination of the Evaporating Fields
}

\author{
O. Golubev
}

\section{To cite this version:}

O. Golubev. A New Experimental Method of the Determination of the Evaporating Fields. Journal de Physique IV Proceedings, 1996, 06 (C5), pp.C5-153-C5-158. 10.1051/jp4:1996525 . jpa-00254404

\section{HAL Id: jpa-00254404 https://hal.science/jpa-00254404}

Submitted on 1 Jan 1996

HAL is a multi-disciplinary open access archive for the deposit and dissemination of scientific research documents, whether they are published or not. The documents may come from teaching and research institutions in France or abroad, or from public or private research centers.
L'archive ouverte pluridisciplinaire HAL, est destinée au dépôt et à la diffusion de documents scientifiques de niveau recherche, publiés ou non, émanant des établissements d'enseignement et de recherche français ou étrangers, des laboratoires publics ou privés. 


\title{
A New Experimental Method of the Determination of the Evaporating Fields
}

\author{
O.L. Golubev
}

\section{A.F.Ioffe Physical-Technical Institute, Russian Academy of Science, Polytekhnicheskaya 26,} St. Petersburg 194021, Russia

\begin{abstract}
A new experimental method of the determination of the evaporating fields $F_{\mathrm{ev}}$ based on Fowler-Nordheim theory is described. This method fits to any materials both refractory and fusible. Especially this method is effective for the thermo-field microprotrusions. The microprotrusions have usually the radii of curvature $r \sim 10-100 \AA$ and one or some atoms on the top and well-known methods of $F_{e v}$ determination are not suitable. Besides that the values of $F_{e v}$ for this small objects are considerable less in comparison with the $F_{e v}$ for the "large" tips. This method requires for realisation only a simple field electron microscope. The exactness of this method is limited by the exactness of the determination of the field factor $\beta$ by means of Fowler-Nordheim plots and by the applicability of Fowler-Nordheim theory to the microprotrusions.
\end{abstract}

\section{INTRODUCTION}

The process of field evaporation is one of the interesting phenomena of the physics of high electric fields. The discovery of this phenomena by E.W.Muller was the most important success of field emission microscopy [1]. The main characteristic of field evaporation is the value of the evaporating field $F_{e v}$. The well-known methods of $F_{e v}$ determination are based on the observation of the evaporation process with fixed velocity of collapsing rings in field ion microscope. The value of the evaporating voltage $V_{e v}$ is measured and the field factor $\beta$ must be obtained to determine $F_{e v}=\beta V_{e v}$ $(\beta=1 / \mathrm{kr}, \mathrm{r}$-radius, of the tip, $\mathrm{k}$-coefficient of the form). The value $\beta$ can be determined directly [2] from the slope of Fowler-Nordheim plot or by determination of both $r$ and $k$ [3]. The radius $r$ can be obtained from field ion image and $\mathrm{k}$ - from the energy deficit of the imaging gas atoms in the process of field ionisation in the free space field ionisation. One can determine $F_{e v}$ by means of the measuring of best image voltage $\mathrm{V}_{\text {biv }}$ and $\mathrm{F}_{\mathrm{ev}}=\mathrm{F}_{\mathrm{biv}} \mathrm{V}_{\mathrm{ev}} / \mathrm{V}_{\text {biv. }}$. The values of best image fields are well-known for all imaging gases and don't depend on the kind of material. However these methods of $F_{e v}$ determination are not effective in application to the fusible materials. The observation of the surface of these materials with good atomic resolution, the calculation of the number of the collapsing rings and the determination of $r$ and $V_{b i v}$ are very hard problems. The experimental values of $F_{e v}$ are determined only for 14 mainly refractory elements [4]. Especially these methods are useless for the thermo-field microprotrusions. These microprotrusions have $r \sim 10-100 \AA$ and one or some atoms on the top. All the well-known methods of $F_{e v}$ determination require the essential evaporation of the microprotrusion to observe its crystal structure. It is necessary to observe the collapsing rings and to determine $r$. But in this case the value of $F_{e v}$ will describe the tip rather then microprotrusion because the microprotrusions are evaporated at the less $F_{e v}$ in comparison with the "large" tips in consequence of the "size effect" [2]. Although this method of $\mathrm{F}_{\mathrm{ev}}$ determination is suitable both the "large" tips and 
the microprotrusions only the experimental results for the microprotrusions are described in this paper because these data are most interesting.

\section{RESULTS}

A new original method of the determination (estimation) of $F_{e v}$ for the microprotrusions is discussed. This method is based on the Fowler-Nordheim characteristics of the studied tips and requires only the simple field electron microscope for its realisation. At first the initial field factor $\beta_{0}$ is determined for the initial investigated tip by means of Fowler-Nordheim plot because the work function $\varphi$ is well-known for all studied materials. Then a positive voltage $V_{1} \approx 0.5 \mathrm{~F}_{\mathrm{t}} / \beta_{0}$ is applied to the tip $\left(F_{t}\right.$ - theoretical calculated value of $F_{e v}$ for the studied material, the values of $F_{t}$ are wellknown also for the all interesting elements [4] ). The value of $V_{I}$ must be enough small to except field evaporation. After this field treatment the field electron regime is used and the next value $\beta_{1}$ is determined and a positive $V_{2} \approx V_{1}+\left(0.025 F_{1} / \beta_{1}\right)$ is applied again. At first stages of this treatment of the tip by positive $V$ the value of $\beta$ is not changed because field evaporation is absent. The operations of the $\beta_{n}$ determination and the treatment by positive $V_{n} \approx V_{n-1}+\left(0.025 F_{t} / \beta_{n-1}\right)$ are repeated periodically up to determined $\beta_{n}$ will be decrease. The value of the decrease of $\beta_{n}$ must be more than the error of the determination of $\beta_{\mathrm{n}}$. The decrease of $\beta_{\mathrm{n}}$ is conditioned by the field evaporation of the tip and $F_{\mathrm{ev}}=\beta_{\mathrm{n}-1} V_{\mathrm{n}}$ where $\beta_{\mathrm{n}-1}$ - the last value of $\beta$ before its decrease and $V_{n}$ - the first value of $V$ after the decrease of $\beta$. Fig.1 demonstrates the principle of this $F_{e v}$ determination. Field evaporation is absent in interval from $V_{1}$ to $V_{n-1}$ and $\beta$ is not changed, the treatment by voltage $V_{n}$ leads to field evaporation and decrease of $\beta$. The value of $\beta$ decreases up to $\beta_{n}$ and $F_{e v}=\beta_{n-1} V_{n}$.

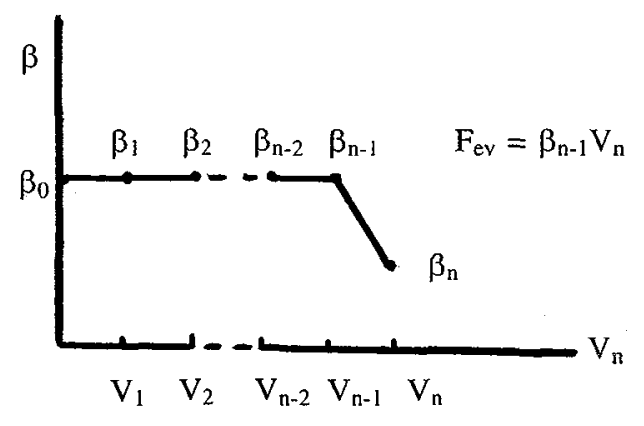

Fig.1

The diagram of $\mathrm{F}_{\mathrm{ev}}$ determination

The experimental plots of the $\mathrm{F}_{\mathrm{ev}}$ determination for $\mathrm{W}$-microprotrusion on the planes $\{012\}$ are shown on Fig.2 and Fig.3. Fig.2 demonstrates the change of $\beta$ depending on the increase of treatment voltage $V_{n}$ and Fig. 3 shows the change the acting field $F$ near the surface depending on $V_{n}$. When the value of $\beta$ is not changed the value of $F$ increases but when $\beta$ begins to decrease $F$ is not changed practically and $F=F_{e v}$. The decrease of $\beta$ is compensated approximately by the rise of $V$. Sometimes 
the value of $F_{e v}$ increases slowly owing to evaporation of the microprotrusion and the increase of its radius of curvature.

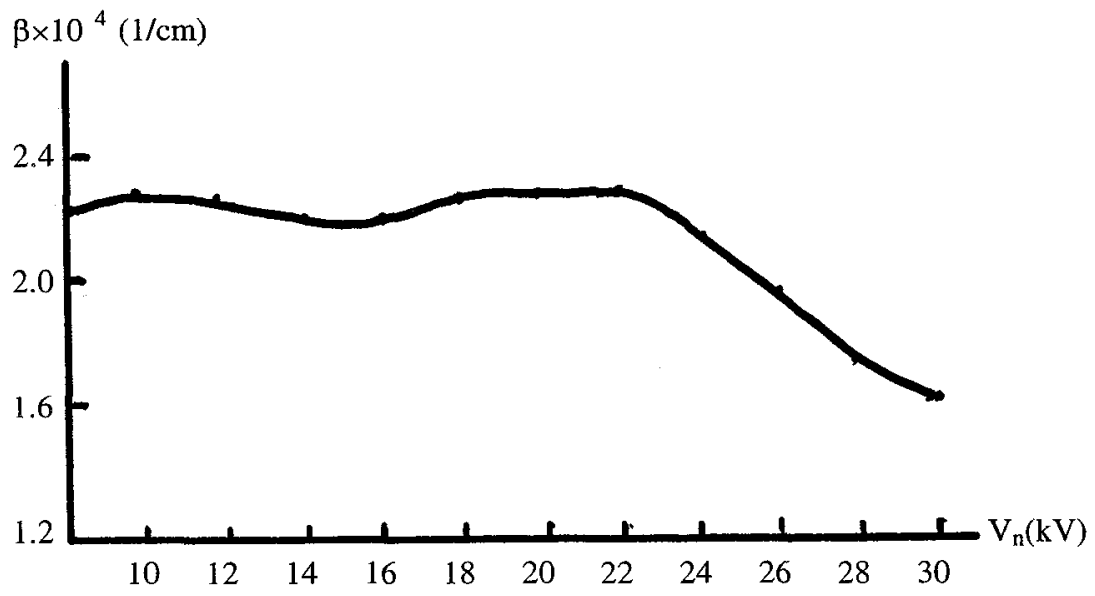

Fig.2

The plot of $\beta(V)$ for the $W$-microprotrusion on $\{012\}$

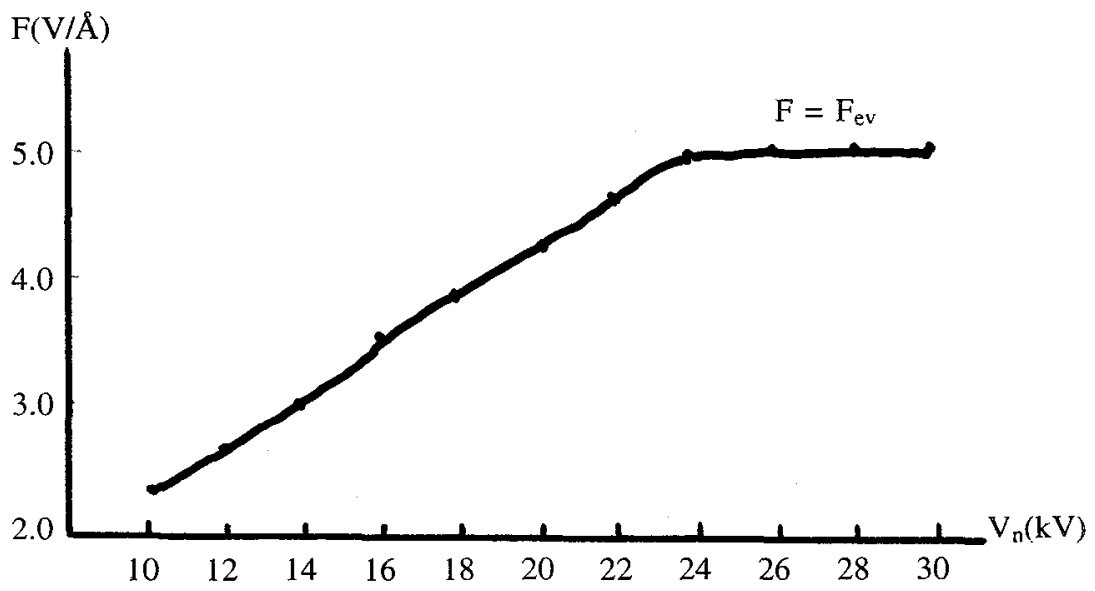

Fig. 3

The plot of $F(V)$ for the $W$-microprotrusion on $\{012\}$

The Table 1 demonstrates the experimental results of the determination of $F_{e v}$ for the microprotrusions of some metals (W, Ta, Ir, Pt) and silicide $\mathrm{WSi}_{2}$ as well as for the microprotrusions which were created on the "thick" layer ( -1000 monolayers $) \mathrm{Si}$ on $\mathrm{W}$. The values of $F_{\mathrm{ev}}$ are significantly less in comparison with the "large" tips of these metals. The evaporating fields for the 
tips with very small radii of curvature are less in comparison with large tips because the decrease of $r$ leads to the rise of the number of the surface atoms in kink position or step edge position [ 2 ]. The interval of the $F_{e v}$ in the Table 1 is determined not by the exactness of $F_{e v}$ measuring. The microprotrusions grow on the various planes of the tip and have different crystal structure and different sizes. Therefore there is the interval of the values of the evaporating fields.

The field electron microscope experiments demonstrate that the emission is coming only or mainly from a small area corresponding to the top of microprotrusion. It is complicated question what value of $\varphi$ may be used for microprotrusion with one or some atoms on the top. There are not experimental data concerning to absolute values of work function of the microprotrusions. The average $\varphi$ for annealed tip was used to determine of $F_{\text {ev }}$. The used $\varphi$ are presented in Table 1 . The microprotrusions grow mainly on the rough planes. It is generally assumed that the values of $\varphi$ of these planes are similar to the average values of $\varphi$. Of course if we will use the work function close to $\varphi$ of close-packed planes the values of $F_{e v}$ will be similar to $F_{e v}$ for "large" tips. However, it is doubtful whether that the microprotrusions have the values of $\varphi$ such as close-packed planes. Anyone who prefers to use a different values of work function can re-calculate the values of $F_{e v}$ in Table 1 .

Table 1

The experimental values of $F_{e v}$

\begin{tabular}{cccc} 
Element & $\begin{array}{c}F_{\mathrm{ev}}(\mathrm{V} / \AA) \\
\text { microprotrusions }\end{array}$ & $\begin{array}{c}\mathrm{F}_{\mathrm{ev}}(\mathrm{V} / \AA) \\
\text { "large" tips [4] }\end{array}$ & $\begin{array}{c}\text { used } \varphi \\
(\mathrm{eV})\end{array}$ \\
\hline $\mathrm{W}$ & $4.7-5.1$ & 5.7 & 4.5 \\
$\mathrm{Ta}$ & $3.2-3.4$ & - & 4.2 \\
$\mathrm{Ir}$ & $2.6-3.0$ & 5.0 & 5.0 \\
$\mathrm{Pt}$ & $2.2-2.4$ & 4.8 & 5.3 \\
$\mathrm{WSi}$ & $1.8-2.5$ & - & 4.8 \\
$\mathrm{Si}$ on W & $2.2-2.6$ & - & 4.8 \\
\end{tabular}

It is necessary to increase the treatment voltage $V_{n}$ very slowly in each cycle of field evaporation and $\beta$ determination. The value of the increase of $\mathrm{V}_{\mathrm{n}}$ in each cycle is $\delta \mathrm{V}_{\mathrm{n}} \approx 0.025 \mathrm{~F}_{\mathrm{t}} / \boldsymbol{\beta}_{\mathrm{n}}$. It is approximate value, it may be made more exact for the concrete experimental conditions. For example $F_{\mathrm{t}}=5.7 \mathrm{~V} / \AA$ for $\mathrm{W}, \beta_{\mathrm{n}} \approx(2-3) \times 10^{4} \mathrm{l} / \mathrm{cm}$ for the $\mathrm{W}$-microprotrusions and the typical values of $\delta V_{n} \approx 450-700 \mathrm{~V}$ if $\mathrm{V}_{\mathrm{n}}=10-20 \mathrm{kV}$, for the Pt-microprotrusions the values of $\delta \mathrm{V}_{\mathrm{n}}$ may be less approximately $400-600 \mathrm{~V}$. The less a value of $\delta \mathrm{V}_{\mathrm{n}}$ the better exactness of $F_{\mathrm{ev}}$ determination but too small values of $\delta V_{n}$ lead to the increase of experimental time. 


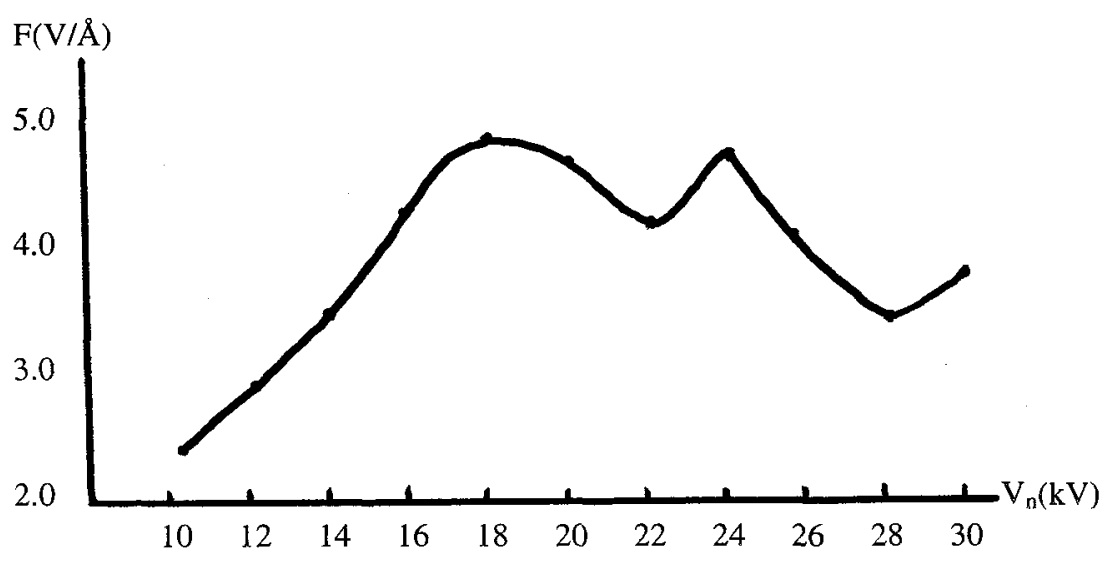

Fig.4

The dependence $\mathrm{F}(\mathrm{V})$ for the $\mathrm{W}$-microprotrusion at the $\mathrm{T}=80 \mathrm{~K}$ and $\mathrm{p}=(5-7) \times 10^{-9}$ torr

This determination of $\mathrm{F}_{\mathrm{ev}}$ can be produced at the any temperature $\mathrm{T}$ of the tip. However the experiments with the microprotrusions at the low $\mathrm{T} \leq 77 \mathrm{~K}$ require very good vacuum conditions not worse than $\sim 10^{-10}-10^{-11}$ torr for the active residual gases. The small microprotrusions are very sensitive to the field adsorption and field etching. The determination of $F_{e v}$ at the $T \leq 77 \mathrm{~K}$ and pressure $\mathrm{p} \geq 10^{-9}$ torr produced the mistakes as a rule. Fig. 4 shows the results of the $\mathrm{F}_{\mathrm{ev}}$ determination for the W-microprotrusions at the $\mathrm{T}=80 \mathrm{~K}$ and $\mathrm{p}=(5-7) \times 10^{-9}$ torr $\left(\mathrm{H}_{2}, \mathrm{~N}_{2}\right)$. When the process of evaporation takes place the dependence $F(V)$ gets very complicated and correct determination of $F_{e v}$ is impossible.

This consideration is correct if we have only one microprotrusion or some identical microprotrusions. If the number of the microprotrusions changes in the process of field evaporation, the dependence $\beta(\mathrm{V})$ may be complicated and this consideration may be not correct. It is necessary to watch closely on the change of the number of the evaporated microprotrusions. However it offers no difficulty to take account the number of the evaporated microprotrusions in the process of the $F_{e v}$ determination.

\section{CONCLUSION}

The main merits of this method include the following:

a - the method is suitable for the any materials both refractory and easily melted,

$b$ - the results can be obtained at any $T$,

$c$ - only the simplest field electron microscope must be used,

$\mathrm{d}$ - only the very simple operations must be produced to determine of $\mathrm{F}_{\mathrm{ev}}$.

The main demerits of this method are as follows:

a - it is impossible to know exactly the velocity of the evaporation during the $F_{e v}$ determination.

$\mathrm{b}$ - the precision of the determination is limited by the exactness of Fowler-Nordheim theory, 
$c$ - it is not quite correct to use of the Fowler-Nordheim theory for the microprotrusions with $r=10-100 \AA$, as leaving a surface electron "sees" a surface as a flat starting to $r \geq 500 \AA$ [5]. If we apply the Fowler-Nordheim theory to the microprotrusions we change the real emitter with not uniform field by a effective emitter with uniform field [6]. The some inaccuracy is inevitable in this case and the real value of $\mathrm{F}_{\mathrm{ev}}$ may be some more in comparison with measured.

Considering these arguments this method can be examined rather as a method of estimation then the measuring of evaporating field for the microprotrusions. However this method is undoubtedly the determination method of the evaporating fields in application to the usual "large" tips. In principle this method allows to obtain of the evaporating fields of any metals from $\mathrm{W}$ and $\mathrm{Ta}$ to $\mathrm{Pb}$ and $\mathrm{Sn}$ using only Fowler-Nordheim characteristics.

\section{REFERENCES}

[1]. Muller E.W. Naturwiss. 29, (1941), pp. 533-541.

[2]. Muller E.W, Young R.D. J. Appl. Phys. 32, (1961), pp. 2425-.2428.

[3]. Sakurai T., Muller E.W. J. Appl. Phys. 48, (1977), pp. 2618-2625.

[4]. Miller M.K. and Smith G.D.W. Atom Probe Microanalysis: Principle and Applications to Material Problems, Material Research Society, Pittsburg, (1989), pp. 269-270.

[5]. Jun He, Cutler P.H. and Miskovsky N.M., Appl. Phys. Lett. 59, 12, (1991), pp. 1-4.

[6].Rabinovich A.A. Surface Sci. 70, (1978), pp. 181-185.. 